\title{
SCHOOL MEDICAL EXAMINATION OF YOUNG CHILDREN
}

\author{
Lieutenant-Colonel O. S. WILLIAMS, ${ }^{*}$ \\ M.R.C.S., L.R.C.P., D.P.H., R.A.M.C. \\ Senior Specialist in Army Health
}

WHEN in 1868 a Dorset Quaker, Forster, first introduced a Bill for a national system of education, there were men of experience in both political parties who pronounced the notion of schools for everyone to be merely an Utopian dream. "You may train your hounds and your pointers" said the honourable member for Newark, "but never the hare or the fox". The sceptics roundly declared that " to suppose that youngsters who have hitherto run wild will prove amenable to discipline or instruction of the classroom is the climax of absurdity". Even Gladstone told Queen Victoria that he considered the author of the Bill to be "a most impracticable man".

Two years later, having won over the Liberal leader, Forster secured the passage of a modified version of his national system of education with the blanks in his educational map being filled in by schools governed by elected Boards and financed from local rates. Despite considerable misgivings, the Conservatives decided to complete what the Liberals had begun; and in 1878 Disraeli decided to extend Forster's Act by a supplementary Bill making school attendance at once universal, free of school fees and compulsory.

The way was now clear for the introduction of a school health service and its early acceptance as an instrument of health policy was virtually decided by the revelations of the Boer War recruitment campaign, which had showed the high proportion of recruits who had to be rejected on the grounds of poor physique, disease and physical disability thus leading to the appointment of an Inter-departmental Committee on Physical Deterioration in 1904. The enlightened recommendations of this Committee found expression in legislative form in many Acts passed during the first quarter of the century, among them, the Education Acts of 1906 and 1907. Under the first of these school meals had to be provided for destitute children while the 1907 Act-the Education (Administrative Provisions) Act enabled Education Authorities to institute school medical inspection and to provide medical attendance.

Once established, the school health service was steadily widened in scope to include provision for the treatment of minor ailments and special defects, for the improvement of child nutrition and for the ascertainment and grading of handicapped children requiring special education suited to their needs. There was indeed little to amend and little to add when the comprehensive enabling Education Act of 1944 became law.

"Doing school medicals" has never been a popular task with doctors. It has been and still is regarded as a dull, wearisome and rather useless chore. It would seem that this attitude has developed over the years because of the pressure imposed on school doctors by local health authorities to get through these examinations as quickly as possible so that they would be available for other duties. An attempt will be made in this

\footnotetext{
*Received in August 1964, Lieutenant-Colonel Williams died in April 1965.
} 
article to show that these examinations so far from being boring and purposeless can be made both interesting and rewarding.

\section{Preliminaries to the Examination}

Time in the medical examination of young children is essential. The amount required to take an adequate history and to do satisfactory examination of a child is about 30 minutes. This allows the doctor to do his work thoroughly and without haste. Moreover it enables him to run a satisfactory appointment system. For obvious reasons this method of examining children is popular not only with parents but also the teachers. It is often astonishing what obstacles a mother will overcome to be present at her child's initial school medical examination. It is as well that this is so since her presence is the key to success in this work. It is for this reason that these examinations should never take place in the mornings; they must always be arranged for the afternoons.

It is essential to establish the best possible teacher/doctor relationship from the outset. The doctor should not delegate to a subordinate the matter of arranging details. of the examination. The doctor himself must do this directly with the head-teacher or school secretary. Not only does this courtesy help good relations but it may well result in obtaining better working conditions and more consideration for the doctor. When good relations have been established, the doctor will be surprised by the amount of useful background information that the head-teacher can give him about the children and their parents. So it is very worthwhile to get to the school ten minutes or so before the examinations are due to start when the head-teacher will gladly brief the doctor with any relevant information about the children he will be seeing that afternoon. In return the doctor should make a point of seeing the head-teacher at the end of the afternoon to tell him or her of anything about the children which the head-teacher should know. It is at this time that the doctor should also tell the teacher of any limitations that should be placed on the child's activities in school or if he or she must be given a special place in class and so on.

It is, also, worthwhile for the school doctor to get to know the other members of the staff and to learn of their problems. Very frequently a child that a teacher is worried about as an educational problem turns out on discussion to be a medical one. The doctor should also take an interest in the hygiene of the school and, in particular, that of the school kitchen. He should make a point of joining the staff and the pupils for the midday meal two or three times a term. Finally the doctor will be surprised how much enjoyment he will derive from attending the school functions-plays, concerts, sports meetings, speech days, exhibitions and the like. After all it is well recognised that the best amateur actors are school children.

\section{History taking}

The parents are invariably told when it is proposed to examine a child and are sent a consent form which they are asked to complete and sign. Amongst other information the parents should enter on this proforma is the name of the child, details of any past illnesses, the sex and year of birth of any other children in the family as well as details of the child's immunological state. This form is available to the doctor at the time of the examination. If the child is not adequately immunised, the doctor must persuade the mother at this interview to have this done and the necessary arrangements can usually 
be made there and then. It is best to start by asking the mother whether she has any special worries about her child. Having noted the reply she should be told that this will be gone into thoroughly at the appropriate stage in the child's history. The doctor should then proceed to enquire about the mother's obstetric history and she must be asked as specific questions. whether she had any of the infectious diseases, taken any drugs or had any accidents during this period. She should be questioned about the length of her labour, whether the child was premature or, whether there were any difficulties in labour and if instruments were used. The birth weight and the method of feeding must be determined. The mother. should be then asked if the baby's condition gave rise to any anxiety immediately after birth, during the first 24 hours, the first week, and the first month. The child's illnesses since that time should then be discussed; it is at this point that any specific worry of the mother should be gone into at length:* The mother should be questioned as to the ages of the child when it could first walk unaided, say its first-recognisable word, utter its first phrases and when control of the bladder by day and by night and of the bowel was first established. A good deal of useful information about the social and environmental aspects of the child's home background can be obtained by getting the mother to describe with as much detail as she can a typical day in the life of her child from the moment of waking until it goes to sleep. Questions should be put about the child's ability to wash and dress itself, to guard itself against common danger and to find its way about. The mother must give details of meals and his/her play activities both inside the home and out. The child's appetite and sleeping habits must be gone into. Enquiries must be made about the child's relations with others such as the parents, its siblings, other relations, teachers and children. In particular, any possibility of jealousy, aggression, undue quarrelling and temper tantrums must be discussed at length. Mothers frequently complain that their husbands tease their children and that this often brings on 'a temper tantrum. It should be impressed on mothers that adults must never tease children since they are quite unable to comprehend it. Young children are only able to realise that in some obscure way it is directed against them. The mother should also be asked if the child ever bites its nails, sucks its thumb or wets the bed. At some point in the discussion on the child's relations with others, the doctor should ask whether the mother, the father or both are able to spend any time during the day exclusively with the child. She should be asked to describe how this time is spent. Should there be any question of the child's speech being retarded the mother must be asked whether she talks to the child constantly when they are alone together. It is still mostly through conversation with adults that children enlarge their vocabulary and learn to say what they mean fluently, exactly and simply. The mother must also be questioned as to whether the child is ever left alone in the house at night, and, if so, warned of the possible future consequences. During the history taking the doctor must remember to ask the mother quite casually whether she has any reason to think that the child has any visual defect or loss of hearing, however slgiht. These questions must be put casually since otherwise the mother is liable to think that the doctor has been primed by the child's teacher that the child does have a defect. Should there be any reason to think that the child does have some hearing loss the name should be noted down for audiometric examination at another time. The history taking should be now complete except for the family history. This should be gone into in the usual way. Finally the child's progress and how it is liking

*There is little point in taking such a detailed obstetric and peri-natal history unless it is indicated. Ed. 
school should be discussed. It is most unusual these days to come across any child who dislikes school.

By this time the doctor should have an accurate medical history of the child as well as good knowledge of the family circumstances, the home background and the child's development progress.

\section{Medical Examination}

Basically the medical examination of school children does not differ from the routine examination of adults although it is an advantage to modify it in some ways. Many children are frightened of doctors, others, particularly girls, dislike undressing themselves before strangers. It is, therefore essential to establish friendly relations with the child as soon as possible; judicious use of a sweet often helps to do this. The child must be encouraged to talk as soon as he enters the examination room. This enables the examiner to assess the child's voice and to note any deviation from the normal as well as the nature of the deviation. The appearance of the child is also important. Some children are apathetic, listless with dull eyes, others are bright, lively and bright eyes and there are various gradations between these two. The child's demeanour and behaviour in the presence of the mother should also be noted. An over dependant child will always keep its eyes fixed on the parent and will not answer any of the doctor's questions or obey any of his instructions until it is assured that the mother agrees. It is equally important to watch the mother's attitude towards her child. Next the gait should be closely observed to see whether it is purposeful or not and to note any peculiarity.

As to the examination itself, it is wise to delay the inspection of the interior of the mouth and of the ears with an auriscope until the end since these procedures often frighten children and make them cry. The limbs and the vertebral column must always be closely examined as to flexibility and range of movements; whilst examining the hands it is easy to look at the nails to see if they are bitten.

In examining boys the scrotal sack and the hernial orifices must not be overlooked. Malposture must be looked for. Lastly one should look at the feet for any deformity. It is a good thing to examine the child's socks and shoes to see if they are ill fitting in any way.

At these examinations the doctor must be able and willing to give mothers advice on such problems as bedwetting, nail biting, food fads, pilfering; temper tantrums, accidents in the home and many other subjects. It is wise to reinforce any advice given by persuading the mother to buy one or other of the excellent health pamphlets that are now readily available. A list of these publications is given at the end. They may be obtained at the cost of a few pence from the local SSAFA sister.

\section{"Draw-a-Man" Test"}

Should it be considered that a child may be dull or backward, confirmation may be quickly obtained by giving the child the Goodenough "Draw-a-Man " test to do. This test is in no way dependent on the child's artistic ability. Between the ages of 3 years and

* Should only be undertaken by a person experienced in giving the test. Ed. 
11 years the test has a high correlation with the Terman Merrill test. The child is given a blank sheet of paper and a pencil or crayon and asked to draw a man or woman or boy or girl which ever it pleases. The time limit is ten or twelve minutes. Any help positive or negative, given to the child whilst it is drawing invalidates the result. The drawing is scored by awarding marks for the features of the body which are included in it. For example, one mark is given for drawing an arm, however indicated, additional marks are scored if the arm is drawn in two dimensions and a third mark if it is joined to the body at the correct or approximately correct point etc. The scoring must be done strictly in accordance with the instructions for the Test. The marks are totalled up and the figure obtained is compared against the given mental age norms. If the mental age of a child is found to be more than 9 months below his chronological age the child should be referred for a Terman Merrill test.

\section{Height and Weight Measurements}

Today some authorities maintain that keeping height and weight measurements of school children is of little value. Indeed apart from London and one or two other towns where measurements of height and weight of a sample of school children are made at 5 yearly intervals, reports on the periodic measurements of school children are published in less than a score of 146 local education authority areas. But these measurements, together with the result of the school doctor's clinical examination give an assessment of the physical condition. This index is crude, but none the less, one that has some practical value.

\section{Earlier Maturation and Increased Growth of School Children}

"The ever earlier maturation of children is one of the most astonishing occurrences in human biology to-day ". On average, boys now complete their growth at 17 years of age compared with 23 years of age in 1900: On average also, menstruation begins in girls at about $13 \frac{1}{2}$ years of age whereas a century ago it occurred at about 17 years of age; since then the age of onset has been about 4 months earlier per decade. In many girls it begins earlier; in Nottingham, for example, 140 girls under 11 years of age in junior schools, in 1960, were already menstruating.

Between 1949 and 1959 the average height of London school children increased by about $0.5 \mathrm{~cm}$. at 5 years of age, by $1.5 \mathrm{~cm}$. at 10 years of age, and by $3.5 \mathrm{~cm}$. thereafter, except that for girls aged 14 and 15 the gains were smaller. During the same period the average weight of children increased by about $0.3 \mathrm{~kg}$. at 5 years of age, by about $1.5 \mathrm{~kg}$. at 10 years of age, and by about $3 \mathrm{~kg}$. at 11-12 years of age; thereafter boys increased in weight by $4-5 \mathrm{~kg}$. at 13 years, and by $3 \frac{1}{2} \mathrm{kgs}$. at 15 years of age; for girls the increased weight was $3 \frac{1}{2} \mathrm{~kg}$. at 13 years of age but only $0.8 \mathrm{~kg}$. at 15 years of age. The average height and weight of London school children aged $5 \frac{1}{2}$ and $13 \frac{1}{2}$ years, from 1905-12 to 1959 are given in Table I (Ministry of Education-1962).

\section{Vision Testing}

The SNELLEN test chart is the simplest and most valuable piece of equipment for the testing of vision. It has been found that the vision of the great majority of 5 year old entrants can be tested satisfactorily by this means, but for those who fail to recognise the letters on the SNELLEN chart other methods must be used. The letter " $E$ " test is 
Table I

\begin{tabular}{|c|c|c|c|c|c|c|c|c|}
\hline \multirow{3}{*}{ YEAR } & \multicolumn{4}{|c|}{$\begin{array}{l}\text { Average height } \\
\text { (centimetres) }\end{array}$} & \multicolumn{4}{|c|}{$\begin{array}{l}\text { Average height } \\
\text { (kilogrammes) }\end{array}$} \\
\hline & \multicolumn{2}{|c|}{5.5 years } & \multicolumn{2}{|c|}{13.5 years } & \multicolumn{2}{|c|}{5.5 years } & \multicolumn{2}{|c|}{13.5 years } \\
\hline & Boys & Girls & Boys & Girls & Boys & Girls & Boys & Girls \\
\hline $\begin{array}{l}1905-12 \\
1938 \\
1949 \\
1954 \\
1959\end{array}$ & $\begin{array}{l}104.0 \\
109.1 \\
110.5 \\
111.1 \\
110.9\end{array}$ & $\begin{array}{l}103.0 \\
108.4 \\
109.8 \\
110.2 \\
110.2\end{array}$ & $\begin{array}{l}143.1 \\
149.0 \\
152.2 \\
154.0 \\
155.8\end{array}$ & $\begin{array}{l}146.8 \\
152.2 \\
153.7 \\
155.4 \\
156.4\end{array}$ & $\begin{array}{l}17.00 \\
19.40 \\
19.59 \\
19.90 \\
19.92\end{array}$ & $\begin{array}{l}16.80 \\
18.90 \\
19.12 \\
19.38 \\
19.44\end{array}$ & $\begin{array}{l}36.40 \\
41.10 \\
42.76 \\
44.32 \\
46.97\end{array}$ & $\begin{array}{l}37.70 \\
43.80 \\
45.47 \\
46.21 \\
48.99\end{array}$ \\
\hline
\end{tabular}

one of the most popular and reliable of these; it is even possible to test the vision of young deaf children by this mean's. Several types of pictorial tests depicting animals and other objects familiar to young children are also employed, but a criticism of some of them is that they do not conform to the SNELLEN principle that the width of the lines composing a figure must be one-fifth of the width of the figure. A hand test in which the child holds its hand in the same direction as hands printed according to the SNELLEN principle on a test chart, is useful and, like the moveable letter " $E$ " can be played as a game. False results will occur if the children are not placed at the correct distance from the test card. In many instances this difficulty arises as a result of the poor accommodation which is used for the purpose; in others the examining doctors are not skilful at fixing distances, so the provision of a cord, 20 feet in length, is helpful.

\section{Medical Records}

Each child has its own medical record card. All findings, positive and negative, should be entered on this card as soon as each examination is completed. A brief description of any defect found must be entered in the appropriate space and a note made of the advice given and the proposed disposal. For his own information the doctor should keep his own notes on the children he sees. These may be made on the proforma, already brought by the parent, as the examination goes on. It is convenient to use this form as it will already have entered on it the child's name, date of birth, address, date of birth of the siblings, details of past illnesses and details of its immunisation state. If it is proposed that the child should be referred for specialist advice or for any other form of investigation the necessity for this must be explained to the mother. Hospital appointments should be arranged as soon as possible. When the result of such a referral is received the doctor must ensure that it is entered on the school record card without delay.

\section{Results}

Table II below gives the number of 4, 5 and 6 year old children examined in 6 different primary schools in Rhine Area in recent months. The number of defects found amongst them are also given. Those children who were thought to be educationally subnormal (ESN), those considered to be possibly maladjusted in some way and those who had a speech defect are shown separately from children with other defects. The last column gives the ratio of the numbers of children examined to the number of defects found at each school and for the six schools together. 
Table II

\begin{tabular}{|c|c|c|c|c|c|}
\hline & $\begin{array}{c}\text { Nos of } \\
4-6\end{array}$ & \multicolumn{3}{|c|}{ DEFECTS } & \multirow{2}{*}{$\begin{array}{c}\begin{array}{c}\text { Ratio } \\
\text { children } \\
\text { examined }\end{array} \\
\text { Defects }\end{array}$} \\
\hline . & $\begin{array}{l}\text { children } \\
\text { examined }\end{array}$ & $\begin{array}{l}\text { ESN, } \\
\text { Maladjusted } \\
\text { and Speech }\end{array}$ & Others & Total & \\
\hline School A & 75 & $\therefore-$ & 6 & 6 & 12.5 \\
\hline & & & & & 1 \\
\hline School B & 39 & - & 7 & 7 & 5.5 \\
\hline & & & & & 1 \\
\hline School C & 20 & 1 & 4 & 5 & 4.0 \\
\hline & $\therefore$ & & & & $1 \ldots$ \\
\hline School.D & 22 & $\therefore \ldots$ & -7 & 7 & 3.1 \\
\hline & & $\ldots$ & & & 1 \\
\hline School E & 46 & $: 1$ & 14 & 15 & 3.07 \\
\hline & & & & & 1 \\
\hline School F & 57 & 26. & 22 & 48 & 1.18 \\
\hline & & & & & 1 \\
\hline Totals & 259 & 28 & 60 & 88 & 2.9 \\
\hline$\therefore$. & & $\because$ & & & 1 \\
\hline
\end{tabular}

In all 259 children were examined. Between them they have a total of 88 defects. The ratio of children examined to defects found is therefore 2.9 to 1 . The difference in the ratios in the six schools are clearly shown in the last column, they vary from 12.5 to 1 at School A to 1.18 to 1 at School F. Table II also shows that of a total of 28 ESN, maladjusted and speech defects found no less than 26 were found at School F. At School $F$ the children were examined in accordance with the procedure described above.

\section{Conclusion}

It has been shown that defects are there to be found and that if the school medical examination is carried out without haste and with due care they will be discovered. It will be argued doubtlessly, that the average service doctor is too hard pressed with his many other duties to spare the necessary time for this important work. Although this may have been true in the past, it is no longer so today. The facts are as follows:- No medical officer in BAOR is responsible for more than one Primary School. The largest number of 5 and 6 years old children in any BFES School in BAOR was 240 in April 1964. (Primary Schools are open for 40 weeks a year). It is extremely unlikely that more than 160 of the 240 would require examination during the year because the rest would have been seen the year before. In other words the extent of this great burden amounts to no more than one interesting, rewarding and easy afternoon's work once a week. 
Recently the system of medical examination at school entry, at ages 8, 11, 14 and on school leaving has been replaced by the selective system. In it children are only given a full medical examination during their first term and their last, while at any age special medical examinations are carried out on pupils previously noted by the medical officer or referred by parents, teachers, S.S.A.F.A. sisters or child pyschologists.

\section{Summary}

1. A method of examining young school children is described.

2. Using this method in one school 48 defects were found in 57 children, giving a ratio of 1 defect for 1.18 children. In five other similar schools this ratio varied from 1 defect for 12.5 children to 1 defect for 3.07 children. The overall ratio for the six schools was 1 defect for 2.9 children. In all the six schools 259 children were examined.

\section{REFERENCE}

InGHAm F. J. (1964). The Health of Army Families. J. roy. Army med. Cps 110, 203.

\section{USEFUL REFERENCE BOOKS}

Burt, C.-The Backward Child. Univ. Lond. Press. $35 \mathrm{~s}$.

BurT, C.--The Maladjusted Child. Univ. Lond. Press. $35 \mathrm{~s}$.

BuRT, C.-The Causes and Treatment of Backwardness. Univ. Lond. Press. $8 \mathrm{~s} .6 \mathrm{~d}$.

GamiLIN, R.-Modern School Hygiene. Aberdeen Press.

Min. Education.-Fealth of the School Child. H.M.S.O. 10s. 6d.

Heaton-Ward, W.-Mental Subnormality. Wright. 6s.

VALENTINE, M.-An Introduction to Psychiatry. Livingstone. $21 \mathrm{~s}$.

Mth. Bull. Minist. Hith. Lab. Serv.

SHERIDON, M. D.--The Development Progress of Irfants and Young Children. H.M.S.O. 1s. 3d.

CRITCHLEY, MacD.-Developmental Dyslexia. Heinemann. 25s.

Holman, P.--Bed-wetting. Central Council Health Education.

\section{USEFUL HEALTH PAMPHLETS}

Ross Labs. Pamphlets:-

(a) Seeing our Children in Focus.

(b) How to be Parent and Like it.

(c) Your Children's Quarrels.

(d) Your Children's Fears.

Pamphlets by Simmons, E. (obtainable from S.S.A.F.A. Sisters-1/1d. for the ten leaflets).
(a) Thumb Sucking.
(b) Bed-wetting.
(f) Jealousy.
(c) Temper Tantrum.
(d) Sleep.
(e) Destructiveness.
(g) Fear.
(h) Stealing.
(i) Lying.
(j) Play.

Central Council of Health Education.

Bed-wetting-Holman, Patricia 